\title{
VAPOR PRESSURE OF VX
}

James H. Buchanan

Leonard C. Buettner

Ann B. Butrow

David E. Tevault

RESEARCH AND TECHNOLOGY DIRECTORATE

November 1999

Approved for public release;

distribution is unlimited.

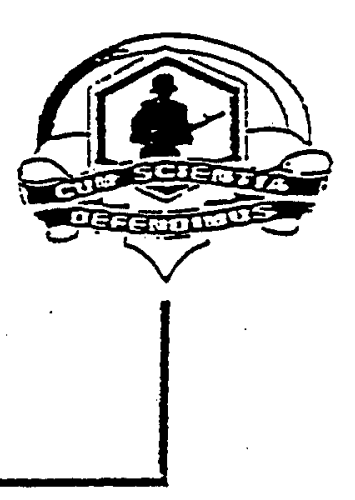

Aberdeen Proving Ground, MD 21010-5424

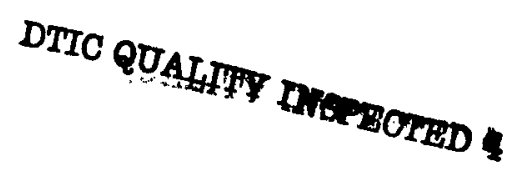


Disclaimer

The findings in this report are not to be construed as an official Department of the Army position unless so designated by other authorizing documents. 
Public reporting burden for this collection of information is estimated to average 1 hour per response, including the time for reviewing instructions, searching existing data sources, gathering and maintaining the data needed, and completing and reviewing the collection of information. Send comments regarding this burden estimate or any other aspect of this collection of information, including suggestions for reducing this burden, to Washington Headquarters Services, Directorate for Information Operations and Reports, 1215 Jefferson Davis Highway, Suite 1204, Arlington, VA 22202-4302, and to the Office of Management and Budget, Paperwork Reduction Project (0704-0188), Washington, DC 20503.

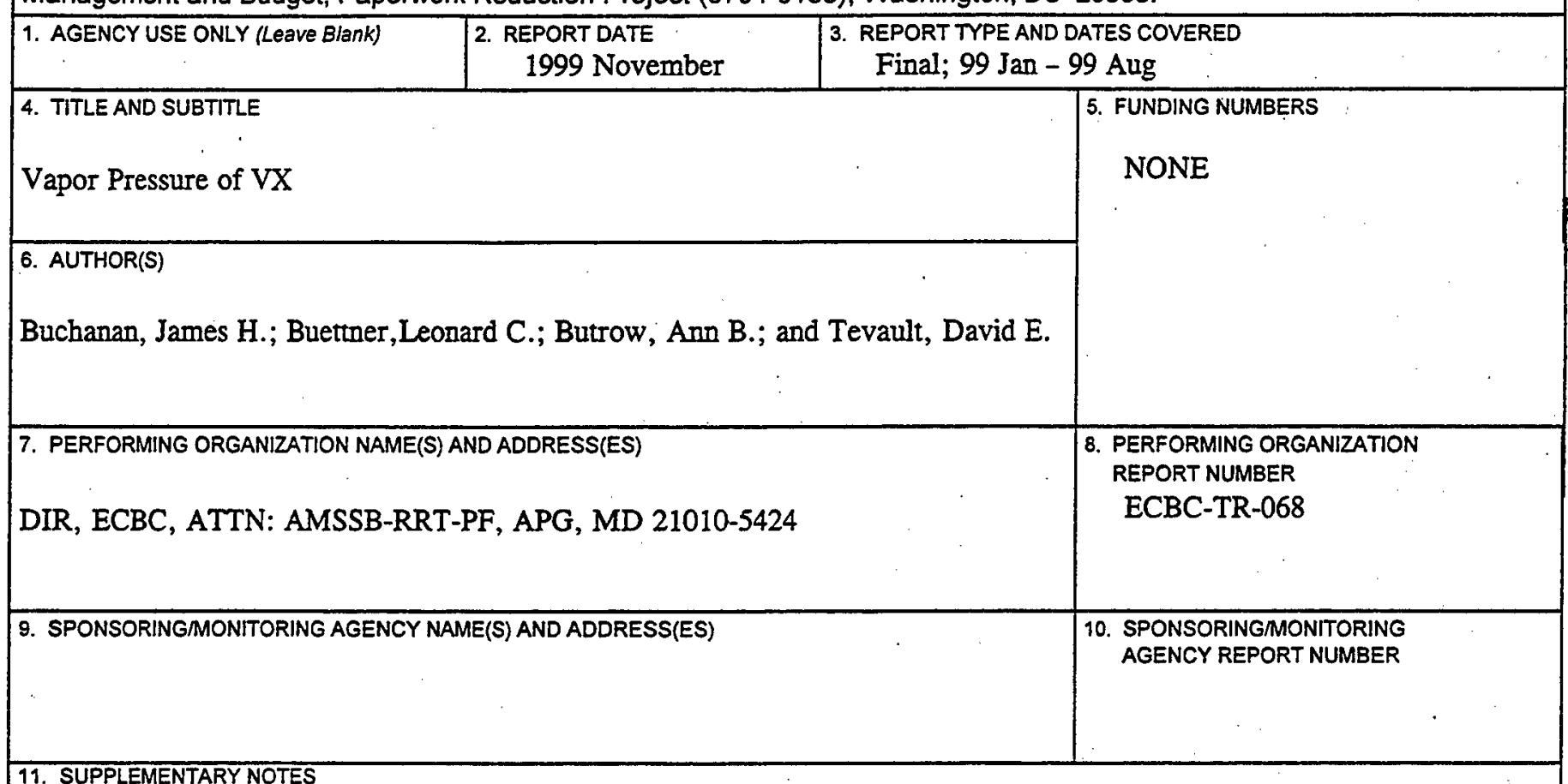

11. SUPPLEMENTARYNOTES

12a. DISTRIBUTIONIAVAILABILITY STATEMENT

12b. DISTRIBUTION CODE

Approved for public release; distribution is unlimited.

13. ABSTRACT (Maximum 200 Words

O-ethyl-S-(diisopropylaminoethly) methyl phosphonothiolate (VX) vapor pressure has been measured using a modified ASTM method in which a carrier gas was slowly passed over the liquid phase, and the saturated effluent was analyzed. Data measured in the current work has extended the low end of the range of measured VX vapor pressures from 30 to $-13{ }^{\circ} \mathrm{C}$, which represents well over two orders of magnitude lower $\mathrm{VX}$ vapor pressure than previously documented and provides a direct assessment of VX volatility over a majority of the ambient range for the first time.

\begin{tabular}{|c|c|c|c|}
\hline \multirow[t]{2}{*}{$\begin{array}{l}\text { 14. SUBJECT TERMS } \\
\text { VX } \\
\text { Vapor pressure }\end{array}$} & \multirow{2}{*}{\multicolumn{2}{|c|}{ - }} & $\begin{array}{l}\text { 15. NUMBER OF PAGES } \\
19\end{array}$ \\
\hline & & & 16. PRICE CODE \\
\hline $\begin{array}{l}\text { 17. SECURITY CLASSIFICATION } \\
\text { OF REPORT } \\
\text { UNCLASSIFIED }\end{array}$ & $\begin{array}{l}\text { 18. SECURITY CLASSIFICATION } \\
\text { OF THIS PAGE } \\
\text { UNCLASSIFIED }\end{array}$ & $\begin{array}{l}\text { 19. SECURITY CLASSIFICATION } \\
\text { OF ABSTRACT } \\
\text { UNCLASSIFIED }\end{array}$ & $\begin{array}{l}\text { 20. LIMITATION OF ABSTRACT } \\
U L\end{array}$ \\
\hline NSN 7540-01-280-5500 & & & $\begin{array}{l}\text { ard Form } 298 \text { (Rev. 2-89) } \\
\text { ribed by ANSi Std. Z39-18 } \\
02\end{array}$ \\
\hline
\end{tabular}





\section{PREFACE}

The work was started in January 1999 and completed in August 1999.

The use of either trade or manufacturers' names in this report does not constitute an official endorsement of any commercial products. This report may not be cited for purposes of advertisement.

This report has been approved for public release. Registered users should request additional copies from the Defense Technical Information Center; unregistered users should direct such requests to the National Technical Information Service.

\section{Acknowledgments}

The authors gratefully acknowledge the technical assistance provided by Thomas E. Rosso, Dennis K. Rohrbaugh, Linda L. Szafraniec, William T. Beaudry, and a helpful discussion with Dr. James J. Savage. 
Blank 


\section{CONTENTS}

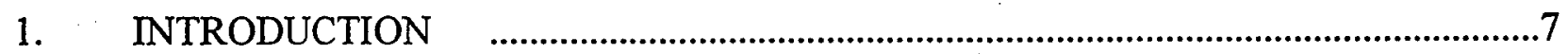

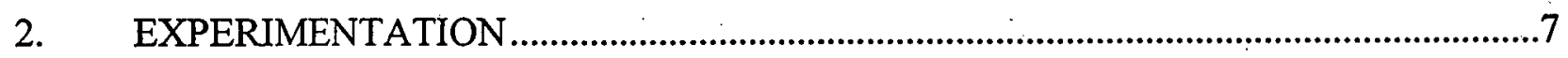

3. RESULTS

4. DISCUSSION

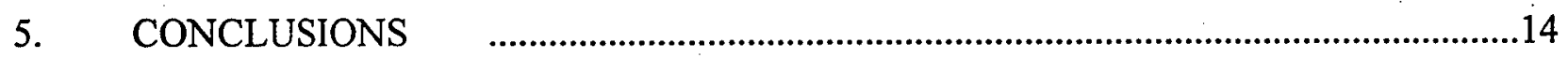

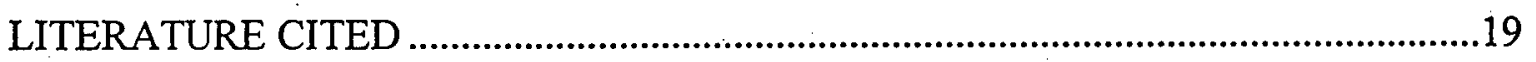





\section{VAPOR PRESSURE OF VX}

\section{INTRODUCTION}

The vapor pressure of VX has been measured previously between 108 and $231^{\circ} \mathrm{C}$ using differential thermal analysis ${ }^{1}$ and between 52 and $100^{\circ} \mathrm{C}$ using Knudsen effusion ${ }^{2}$. The lower limit of previous work was $52^{\circ} \mathrm{C}$ where the vapor pressure was reported to be 0.0118 Torr $(1.57 \mathrm{~Pa})$. While equations are available to extrapolate beyond the experimental range, the errors associated with these calculated vapor pressures increase as the extrapolation gets farther from measured data. Therefore, it is desirable to have measured data over as wide a range as possible. The current work employs a modified ASTM gas saturation method ${ }^{3}$ and extends the temperature range for measured $\mathrm{VX}$ vapor pressure data to $-13^{\circ} \mathrm{C}$, which allows vapor pressure measurements for VX well over 3 orders of magnitude lower than previously reported.

Vapor pressure data are used for a wide variety of applications including assessing evaporation rates at ambient conditions, calibration of detectors, vapor generator design for evaluation of physiological effects resulting from exposure to toxic vapors, and evaluation of vapor filtration performance. One method used to generate and control the concentration of vapors of interest in a gas stream is to pass an inert carrier gas, e.g., dry nitrogen or helium, over a condensed material maintained in a container at a controlled temperature. If the ambient pressure, carrier flow rate, and vapor pressure of the liquid are known, the concentration exiting the generator can be calculated by use of the ideal gas law. Conversely, if the ambient pressure and carrier gas flow rate are known and the concentration can be measured, the vapor pressure can be inferred. Once the vapor pressure dependence on temperature is fully characterized, effluent concentration can be precisely controlled by changing the carrier flow rate and temperature. Accordingly, it is important to have an accurate knowledge of the temperaturevapor pressure relationship for each vapor of interest.

\section{EXPERIMENTATION}

Saturated VX vapor streams were generated by flowing nitrogen carrier gas at 30.0 standard cubic centimeters per $\min (\mathrm{sccm})$ through a glass vessel, i.e., saturator, containing liquid VX, shown schematically in Figure 1. The saturator has two vertical 7-mm o.d. tubes, about $20 \mathrm{~cm}$ long, connected to either end of a $100-\mathrm{mm}$ long, $25-\mathrm{mm}$ o.d. cylindrical horizontal tube, which held the liquid. The horizontal tube contained a concentric hollow ceramic cylinder in contact with the liquid sample fabricated in a manner to allow the carrier to make three passes along the length of the tube prior to exiting and to increase the contact area since the sample wetted the rough ceramic surface. This geometry provided for a carrier gas residence time of about $1 \mathrm{~min}$ in the saturator.

In this work, the saturator was loaded with $7 \mathrm{~g}$ of neat VX, Chemical Agent Standard Analytical Reference Material (CASARM), Lot Number VX-U-2128-CTF-N, 94.6\%, used as received. The VX sample used for these measurements was analyzed before data were collected 
by ${ }^{31}$ P NMR spectroscopy, Gas Chromatography (GC)-Mass Spectrometry (MS), and GC using a Thermal Conductivity Detector (TCD). The VX sample used in the vapor pressure study was also analyzed immediately after the vapor pressure data were collected by GC/TCD with no observable change in purity.

The saturated VX stream was sampled by drawing 5-20 sccm of the saturator effluent to the Dynatherm concentrator, a modified ACEM Model 900 (Dynatherm Analytical Instruments Inc., Kelton, PA) system containing a tenax adsorbent tube. The flow rate was controlled using a calibrated 10- or 100-sccm mass flow controller (Tylan Model FC-280, Austin, TX), which was connected to the house vacuum for 1-25 min, depending on the amount of VX to be collected, i.e., flow rate and temperature. The saturator effluent was sampled at a "tee" connection $3 \mathrm{~cm}$ downstream of the saturator constant-temperature bath. The sampling line was constructed of 1/16-in. o.d., 0.040-in. i.d. Silico Steel (fused silica lined stainless steel, Restek Corporation., Bellefonte, PA). All connectors between the saturator effluent line "tee" and the concentrator were 316 stainless steel. The concentrator sampling line between the "tee" and the ACEM was heated to ca. $100^{\circ} \mathrm{C}$ to reduce sampling line losses and thus reduce the time needed to achieve steady state following sample temperature changes. The ACEM 900 valve box, external six-port valve, and transfer line to the $\mathrm{GC}$ were maintained at $150^{\circ} \mathrm{C}$. The sample was concentrated by the ACEM 900 using the following operating parameters. The temperature of the $10-\mathrm{mm}$ o.d. tenax collection tube was maintained at $35^{\circ} \mathrm{C}$ during the variable 1-25-min sample collection time. A 1-min purge using dry nitrogen was employed as the next step of the sampling process. The sample was rapidly heated to $275^{\circ} \mathrm{C}$ under a flow rate of $20 \mathrm{sccm}$ UHP grade helium for 3 min and transferred to the ACEM 900 tenax focusing trap, which was maintained at $35^{\circ} \mathrm{C}$. Transfer continued for an additional min as the $10-\mathrm{mm}$ o.d. tenax collection tube cooled. The focusing trap was then rapidly heated to $300^{\circ} \mathrm{C}$ under a flow of $8 \mathrm{sccm}$ UHP grade helium for $3 \mathrm{~min}$ to effect sample transfer to the GC column. The GC column (Restek Corporation., Bellefonte, PA), a 30-m x 0.53-mm i.d. fused silica column with 1.0- $\mu \mathrm{m} \mathrm{RTx-1} \mathrm{(polydimethyl-}$ siloxane), was maintained at $50^{\circ} \mathrm{C}$ for $2 \mathrm{~min}$, then heated at a rate of $10^{\circ} \mathrm{C} / \mathrm{min}$ to $200^{\circ} \mathrm{C}$, and maintained at $200^{\circ} \mathrm{C}$ for $5 \mathrm{~min}$ well after the VX had eluted. A Hewlett Packard (HP) Model 5890 Series II GC equipped with a flame-photometric detector and a phosphorus-selective filter (FPDP) was used as the analytical detection system in this work. Helium was used as the GC carrier gas at a flow rate of $8 \mathrm{sccm}$ and as detector make-up gas at a flow rate of $12 \mathrm{sccm}$. Combustion gases used to support the FPDP were air at $100 \mathrm{sccm}$ and hydrogen at $75 \mathrm{sccm}$. Using the instrumentation and operating conditions described, VX eluted at $15.5 \mathrm{~min}$, which represents a $\mathrm{GC}$ column temperature of $185^{\circ} \mathrm{C}$. The FPDP minimum detectable limit for VX was determined to be $0.3 \mathrm{ng}$ with a signal-to-noise ratio $>2$. Initial saturator $\mathrm{GC}$ analyses revealed more than 20 phosphorus-containing compounds. Surprisingly, the VX peak measured from the saturator effluent initially accounted for only about 7\% of the total GC peak area as opposed to the calibration and liquid analysis data which showed that the VX peak accounted for $95 \%$ of the total area. The prominence of the VX GC peak from the saturator effluent increased slightly during the 2 weeks of data measurement to a maximum of $9 \%$ of the total area. The low abundance of VX in the vapor phase is a consequence of its low volatility compared to the known impurities, most of which have considerably higher volatility than VX. The slow clean up of VX has also been observed in our laboratory for similar low-volatility materials. This phenomenon does not present a problem for vapor pressure calculation as discussed below. 
A "stock" solution for calibration was prepared by adding $5 \mu \mathrm{L}$ of neat VX to about $20 \mathrm{~mL}$ of isopropyl alcohol (IPA) using a 5- $\mu \mathrm{L}$ Drummond Model 105 Microdispenser (Drummond Scientific Company, Broomall, PA) and diluting to $25 \mathrm{~mL}$ with IPA. Converting this volume of VX to mass using the liquid density at room temperature $\left(1.0103 \mathrm{~g} / \mathrm{ml}\right.$ at $\left.22.5^{\circ} \mathrm{C}\right)$ and correcting for VX purity (94.6\%) resulted in a solution with a concentration of $191.2 \mathrm{ng}$ VX per microliter of IPA. A calibration standard was prepared from this "stock" solution to span the experimental data range of interest. A 7.648-ng/ $\mu \mathrm{L}$ (28.6 micromolar) standard was prepared by diluting $400 \mu \mathrm{L}$ of the "stock" solution to $10 \mathrm{~mL}$ with IPA using a 200- $\mu \mathrm{L}$ (Drummond Model 385) Microdispenser (Drummond Scientific Company, Broomall, PA). The "stock" solution and calibration standard were prepared using volumetric flasks that had been preconditioned with similar concentrations of VX in IPA for about 2 weeks.

All calibrations were performed using standards prepared from the stock solution on the same day. The FPDP was calibrated by making 1-6- $\mu \mathrm{L}$ injections of VX-isopropyl alcohol standards onto the 10-mm o.d. tenax collection tube mounted horizontally in the Dynatherm Model 10 Tube Conditioner (Dynatherm Analytical Instruments, Incorporated, Kelton, PA) at a laboratory temperature of $22.5^{\circ} \mathrm{C}$ under a $30-\mathrm{sccm}$ flow of nitrogen carrier gas for $2 \mathrm{~min}$. After each injection was made, the tenax tube was placed into the ACEM 900 for transfer to the GC column for analysis. ACEM 900 and GC operating parameters were identical to those used for experimental data acquisition. The resulting calibration curve was generated by plotting FPDP area counts versus mass of VX injected and was slightly non-linear. The quadratic equation shown in Equation 1 described the calibration data most accurately.

$$
\text { Equation (1) } \quad A=0.003045 \cdot m_{v x}{ }^{2}+0.3875 \cdot m_{v x}
$$

where

$$
\begin{aligned}
& \mathrm{m}_{\mathrm{VX}}=\text { mass of VX (ng) injected } \\
& \mathrm{A}=\mathrm{GC} \text { area (millions of area counts) }
\end{aligned}
$$

The resulting raw data and calibration curve are shown in Figure 2. The slight nonlinearity is due to the presence of sulfur in VX. Similar calibrations performed in our laboratory for compounds containing both phosphorus and sulfur have produced similar results, while calibrations for compounds containing phosphorus only were more linear. The reason for this behavior is overlap of the low-energy tail of the sulfur molecular emissions with the phosphorus filter window near $530 \mathrm{~nm} .{ }^{4}$ As seen in Figure 2, the data scatter of the calibration curve was minimal $\left(R^{2}=0.999\right)$. Two VX calibrations performed several months apart produced similar calibration results. The linear and quadratic coefficients of the calibration curve are indicative of the selectivity of the phosphorus filter. In this case, the phosphorus selectivity appears to be higher than $99 \%$, although this fraction will also depend on other factors, including relative intensity of the phosphorus and sulfur emissions and specific filter characteristics.

The temperature of the sample container was controlled by immersing it in a waterethylene glycol bath. The temperature of the bath was measured to within $0.1^{\circ} \mathrm{C}$ using a calibrated thermometer. The ambient pressure was measured periodically during each run using a Princo Instruments Nova Model mercury manometer (Princo Instruments, Incorporated, Southampton, PA). All manometer readings were corrected for temperature and latitude 
according to the manufacturer's directions. These readings were used in the vapor pressure calculation as described below. Owing to the experimental design and operating parameters, there should be very little over-pressure inside the saturator. This correction is believed to be very small and has not been used in this work.

Calculation of VX vapor pressure from the mass collected at each temperature was performed using the ideal gas law. The number of moles of nitrogen exiting the saturator was determined from the concentrator flow rate $(\mathrm{sccm})$ and the sampling time. VX mass loss measured in this study was kept in the 30-50 ng range by using longer sample collection times and higher flow rates for the lower temperature measurements. The VX mass was determined by comparing GC areas to those measured in the calibration studies. The derived mass was used to determine the number of moles of VX evaporated. The total number of moles exiting the saturator, i.e., VX and carrier gas, is the sum of the two. VX vapor pressure was calculated using the ideal gas law assumption as shown in equation (2). The calculated vapor pressure was corrected for the sample purity by taking Raoult's Law into account.

Equation (2) $\quad \mathbf{P}_{\mathrm{vx}}=\left(\mathbf{P}_{\text {ambient }} \bullet\left(\mathbf{n}_{\mathrm{vx}} /\left(\mathbf{n}_{\mathrm{vx}}+\mathbf{n}_{\text {carrier }}\right)\right)\right) / \mathbf{y}_{\mathrm{vx}}$

where

$$
\begin{array}{ll}
\mathrm{P}_{\mathrm{vx}} & =\mathrm{VX} \text { vapor pressure in pascals } \\
\mathrm{P}_{\mathrm{ambient}} & =\text { corrected barometric pressure reading }(\mathrm{Pa}) \\
\mathrm{n}_{\mathrm{vx}} & =\text { moles } \mathrm{VX}=\text { measured } \mathrm{VX} \text { mass loss }(\mathrm{g}) /(267.4 \mathrm{~g} / \mathrm{gm} \text { mole }) \\
\mathrm{n}_{\text {carrier }} & =\text { moles carrier }=\text { calibrated flow rate }(\mathrm{sccm}) \cdot \text { time }(\text { minutes }) \cdot(\mathrm{P} / \mathrm{RT}) \\
\mathrm{P} & =101325 \mathrm{~Pa} \\
\mathrm{R} & =8314000 \mathrm{cc}-\mathrm{Pa} / \mathrm{mole}^{\circ} \mathrm{K} \\
\mathrm{T} & =273.16^{\circ} \mathrm{K} \\
\mathrm{y}_{\mathrm{vx}} & =\mathrm{VX} \text { mole fraction }(0.946)
\end{array}
$$

\section{RESULTS}

Analyses of the CASARM sample performed prior to data collection indicated a $94.6 \%$ mole fraction of VX. Most of the significant impurities had been identified and are common to VX samples. Most of these impurities have considerably higher vapor pressure than VX and were reduced by prolonged purging with the carrier gas. The sample was purged for several days at room temperature before initiation of data collection to reduce the concentration of the impurities. This effort was partially successful as indicated by the relative decrease in the GC area attributable to impurities. A much higher success could have been achieved for a smaller sample size, and future saturator cell design will incorporate changes to allow smaller samples to be used.

Vapor pressure measurements were performed using the automatic cycling capability of the vapor concentrator and sampling system. Typically, each sample was collected for between 1 and $25 \mathrm{~min}$ at $5-20 \mathrm{sccm}$ onto the tenax adsorbent. Following sample collection and transfer to the focusing trap, the adsorbate was transferred to the GC, and the GC column was heated from 
$50^{\circ} \mathrm{C}$ to $200^{\circ} \mathrm{C}$ over a $22-m i n$ period. This process took almost $1 \mathrm{hr}$, and the process was repeated until the area under the GC peak for VX was stable. Usually, it took 5-8 hr for the VX area to achieve stability following sample temperature changes, while the higher volatility components responded and stabilized much more quickly.

The raw and corrected vapor pressure data measured in this work are shown in Table 1. Each entry represents an average of at least 10 separate measurements. Since the liquid VX sample mole fraction was only about $95 \%$, the measured vapor pressures were corrected using Raoult's Law. The majority of the data reported here were measured at a saturator flow rate of $30 \mathrm{sccm}$. Two experiments were performed at $50 \mathrm{sccm}$ saturator flow rate once the GC area counts had stabilized for the $20^{\circ} \mathrm{C}$ data point. The insensitivity of calculated VX vapor pressure to flow rate indicates achievement of saturation, even at the higher flow rate.

The VX vapor pressure data measured using the saturator in this work, along with data presented by Savage and Fielder and by Belkin and Brown are plotted in Figure 3. A new Antoine correlation was derived based on all data considered in this report. Comparison of the measured data and calculated vapor pressures over the range under consideration are shown in Figure 3. New Antoine coefficients are listed in Table 2 along with comparisons between the measured and calculated data based on the new Antoine analysis. Table 3 presents calculated VX vapor pressure based on the previous ${ }^{2}$ and new Antoine analyses and calculated VX volatility over the ambient temperature range.

\section{DISCUSSION}

Previous vapor pressure measurements for dimethyl methylphosphonate (DMMP) and distilled water were performed in our laboratory in a similar fashion by directly measuring mass loss. ${ }^{5}$ This simple method worked well for those compounds since their vapor pressures are in a range where sufficient weight loss was observed over a reasonable period of time. The water vapor pressure results were in excellent agreement with literature ${ }^{6}$ data. The DMMP data were consistent with earlier data and lowered the measured data range by about $80^{\circ} \mathrm{C}{ }^{7}$ The direct mass loss method is not suitable for compounds with vapor pressure in the range of VX in the temperature range of interest since measurable changes would require either weeks or months instead of hours or days. Another serious problem for weight-loss methodology for compounds such as VX is the presence of higher-volatility impurities. As a result, the current measurements have resorted to measuring mass loss indirectly using a much more sensitive purge-and-trap gas method coupled with gas chromatographic analysis with FPDP detection to separate VX from its impurities.

Prior vapor pressure measurements performed in this laboratory for DMMP used two saturator vessels very similar to the one used in this work. Those were placed in series to lengthen the contact time between carrier and liquid in an attempt to ensure vapor-liquid equilibrium. That work was performed using higher flow rates than those used in the present work. Measurements in the earlier work showed that vapor-liquid equilibrium was achieved and that very little DMMP was lost from the second saturator for flows as high as $80 \mathrm{sccm}$, which represented the upper flow rate limit of the earlier work. For a variety of reasons, including the more sensitive analytical method and the hazards associated with using large quantities of VX, a single saturator was used in the present work. To demonstrate that the vapor exiting the saturator 
was in equilibrium with the liquid, several VX vapor pressure measurements were done at saturator flow rates of 30 and $50 \mathrm{sccm}$. For these measurements, the derived vapor pressure was independent of flow rate, demonstrating that equilibrium had been achieved at flow rates in this range using a single saturator.

The saturation method used to measure VX vapor pressure in this work has a very significant advantage over mass-loss methods such as direct weighing and Knudsen effusion. That advantage accrues from the GC analysis performed on the effluent. The GC analysis allows a direct assessment of the analyte concentration. In the present case, VX is a minor component of the effluent stream owing to its low vapor pressure compared to the myriad of impurities it contains. A mass-loss method can be used for low-volatility vapors with high-volatility impurities such as for VX, but only with caution to ensure that the sample is purified to the point that the vast majority of the analyzed material is actually the vapor of interest. Analyzing the effluent and separating the analyte of interest gets around this problem if its mole fraction is known since the measured vapor pressure can be corrected to that of the pure compound by use of Raoult's Law. The Antoine fit of the corrected data has been derived for all data listed in Table 1 and is presented as Equation 3.8

\section{Equation (3) $\quad$ In VP (Pascal) $=\mathbf{a - b / ( c + T )}$}

where $a, b$, and $c$ are fit parameters, and $T$ is the absolute temperature.

The reduction of volatile impurities that accompanied prolonged sample purging in the saturator raised questions regarding the sensitivity to this effect of the methods used previously to measure VX vapor pressure. Differential thermal analysis (DTA) measurements are carried out under sufficiently different conditions that purging of volatile compounds should not affect the results. However, the conditions for Knudsen effusion measurements are similar enough to the saturator experiments that this issue needs to be considered.

In DTA, the sample and a thermocouple are loaded into a glass capillary tube, which is then placed in the instrument heating block. The system is stabilized at the desired pressure, and the block is heated until boiling of the liquid is detected based on the time-temperature plot. The technique is rapid, and a data point can be generated in a matter of min. Pure materials produce a sharp endothermic peak with a vertical leading edge as boiling occurs at a constant temperature. The boiling point is defined as the peak onset temperature and is taken at the intersection of tangents to this curve. The presence of impurities tends to broaden the boiling peaks as the boiling range increases, thus changing the peak onset temperature. Due to the speed of the measurement and the fact that the result depends on the boiling temperature of the liquid, concentration of volatile impurities in the vapor should not impact vapor pressure measurements by DTA. As seen in Figure 3, the low end of the DTA data deviate significantly from the Antoine fit. It is possible that slow pumping rates are responsible for the positive deviation. In that case, the local pressure would be slightly higher than the measured pressure and lead to apparently higher than actual vapor pressures. If the DTA data below $1000 \mathrm{~Pa}$ are eliminated, the average error for the remaining data is reduced to below $6 \%$.

In the Knudsen effusion method, vapor pressure is calculated based on weight loss over time as the test material effuses through an orifice of known area at a controlled temperature 
under high vacuum. Measurements are time-consuming since it can take hours to achieve thermal equilibrium under high vacuum. The material effusing from the sample cup is not analyzed, so it is difficult to determine how much of the weight loss is due to impurities rather than the material of interest. On the other hand, the samples are small, so sample purification by distillation should be rapid. The presence of impurities in a sample is indicated by a change in the slope of the weight-vs-time curve. Weight loss data are not used for calculation of the actual vapor pressure until a stabilized rate of weight loss has been established. At this point, it is assumed that the effusing species is the compound of interest. However, this may not be the case if the impurities are close in volatility to the test material or if the sample contains a significant quantity of a lower-volatility component. Calculation of vapor pressure under these conditions assumes that the molecular weight of the effusing species is known. If weight loss attributed solely to the test material actually includes impurities, the calculated result will be inaccurate.

The Antoine equation previously considered to reflect the most accurate vapor pressure data for VX was presented by Savage and Fielder. ${ }^{2}$ That report cites three discrete data sets from which that Antoine equation was generated:

- DTA data, temperature range 108 to $231^{\circ} \mathrm{C}$

- Knudsen data, temperature range 52 to $100^{\circ} \mathrm{C}$

- Knudsen data, temperature range 30 to $40^{\circ} \mathrm{C}$

The DTA data set attributed to Belkin and Brown ${ }^{1}$ will not be discussed further here. Savage and Fielder ${ }^{2}$ cited five laboratory notebooks containing the experimental data. For the higher temperature Knudsen data set, only a typed table of the same temperature/pressure pairs listed in the report could be located in the cited notebooks. None of the detailed raw data typical of a Knudsen notebook entry was found for VX. Savage's notebooks did contain numerous other lengthy entries describing Knudsen experiments with other compounds. These contained comments indicating awareness of the implications of a changing slope with Knudsen weight loss data. This suggests that the VX Knudsen data were treated in a similar manner.

The source of the second data set was not cited by Savage and Fielder. Data between 30 and $40^{\circ} \mathrm{C}$ were measured by Haskell in the mid 1960 s and were documented. ${ }^{1}$ Haskell's notebook contains a discussion by Coulter regarding which experimental points should be used for calculation of the Antoine equation and the reasons supporting his selections. This discussion clearly indicates that for the VX measurements in this lower range, the initial weight loss was due to loss of volatile impurities, and those points were discarded.

The unavailability of raw data for Savage's and Fielder's Knudsen measurements complicates assessment of the literature data but does not justify excluding those points from a new Antoine fit for the combined literature and saturator data sets. If the temperature range of Savage's and Fielder's data covered the high or low end of the temperature range being considered here, an argument could be made to exclude those points. Since the points fall in the middle of the experimental range of all data and have good overall consistency with the other data sets, they were included in calculation of a new VX Antoine equation.

The new Antoine fit to the saturator data produced an average difference between calculated and measured vapor pressures of $1.8 \%$ for the saturator data, $7.0 \%$ for the Knudsen 
data, and $11.6 \%$ for the DTA data, with an overall average difference of $9.0 \%$. The Antoine equation developed by Savage and Fielder is lower by a factor of three than the lowest temperature saturator data to over 1 order of magnitude lower at $-40^{\circ} \mathrm{C}$ (estimated) as seen in Table 3.

\section{CONCLUSIONS}

This work represents the first time that the vapor saturation method in combination with purge-and-trap chromatography has been used to measure the vapor pressure of a CW agent. The methodology employed has a number of advantages over methods previously used for measuring the vapor pressure of toxic, low-volatility materials. The vapor saturation method in combination with very sensitive analytical methods such as the ones used in this study shows great promise for vapor pressure measurements well below $10^{-6}$ Pascal. In addition, the analytical methodology used in the present work gets around sample and effluent purity problems since the vapor(s) of interest are separated by GC and analyzed directly. The vapor pressure of the pure compound can be derived using Raoult's Law if the liquid sample purity is known.

The saturator vapor pressure data measurements have lowered the range of measured VX data by $65^{\circ} \mathrm{C}$. Data measured in this work between -13 and $20^{\circ} \mathrm{C}$ indicate a higher (ca. $33 \%$ ) VX volatility at $25^{\circ} \mathrm{C}$ than predicted by the most recent previous analysis. ${ }^{2}$

Results of this type are important for several applications, including:

- Accurate assessment of liquid VX evaporation rates at ambient conditions

- Design of vapor generators for low-concentration toxicity studies

- Calibration of sensitive $\mathrm{CW}$ agent vapor detectors

- Evaluation of CW agent vapor filter efficiency 


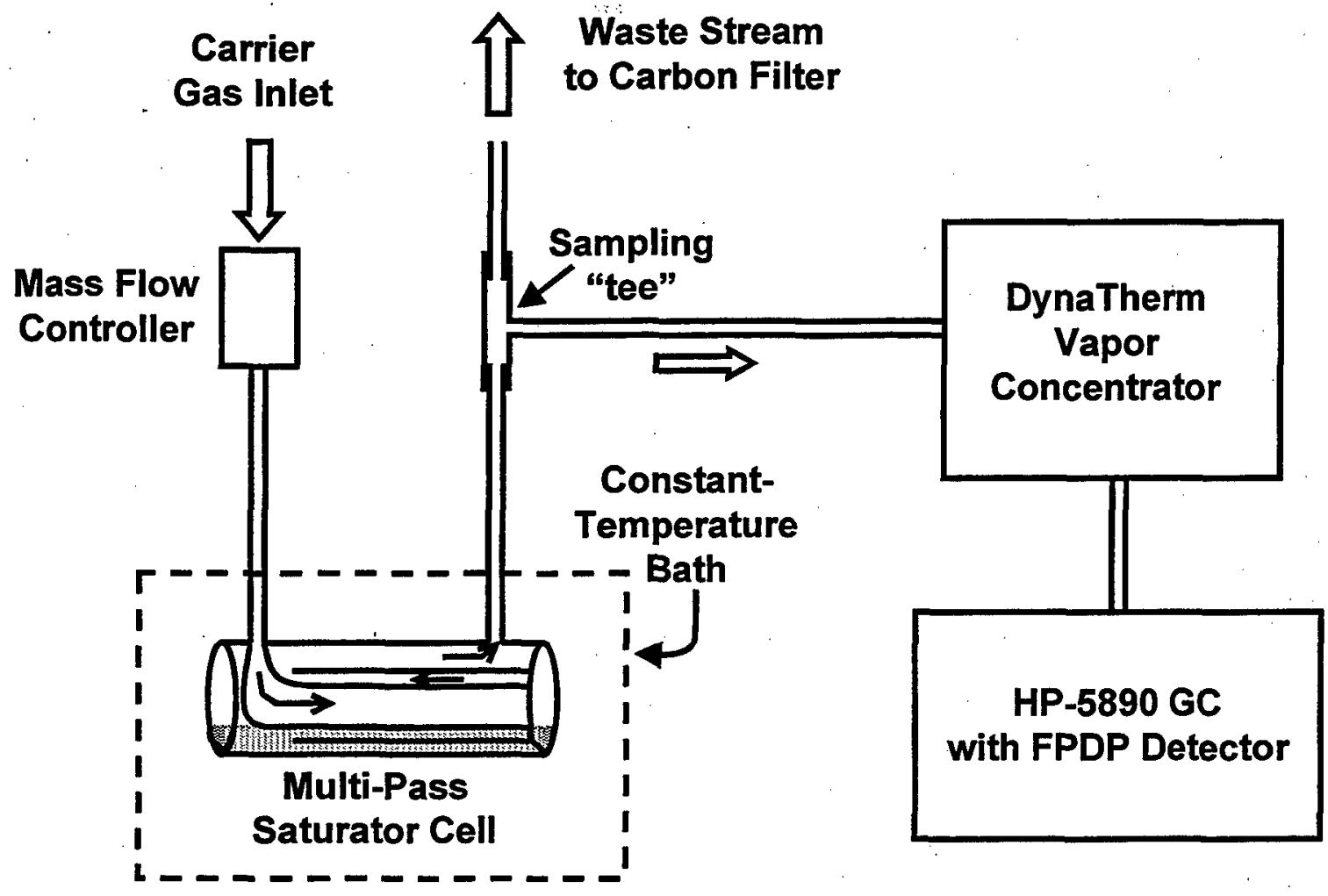

Figure 1. Schematic of Data Acquisition System Used to Measure VX Vapor Pressure.

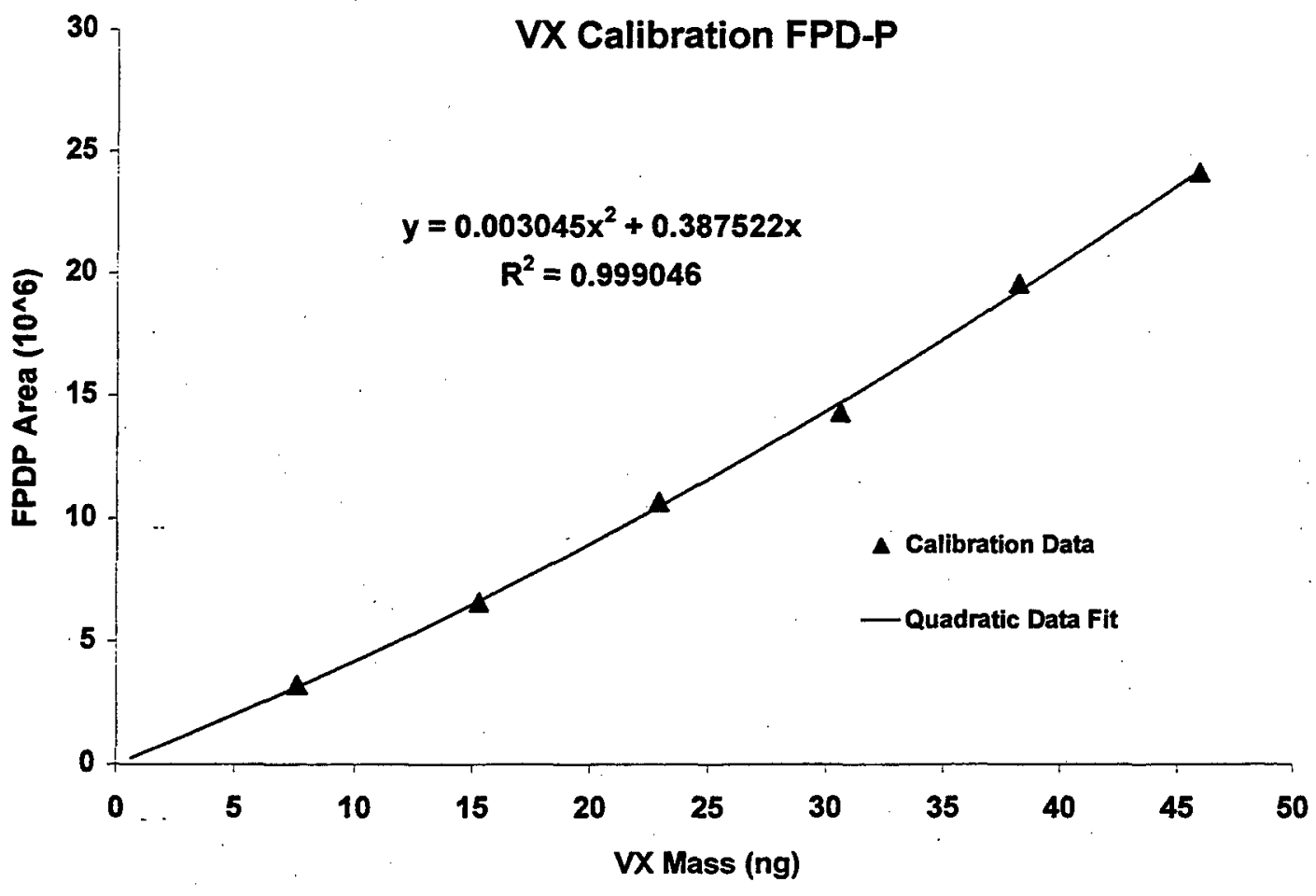

Figure 2. VX Calibration Curve and Analytical Equation 


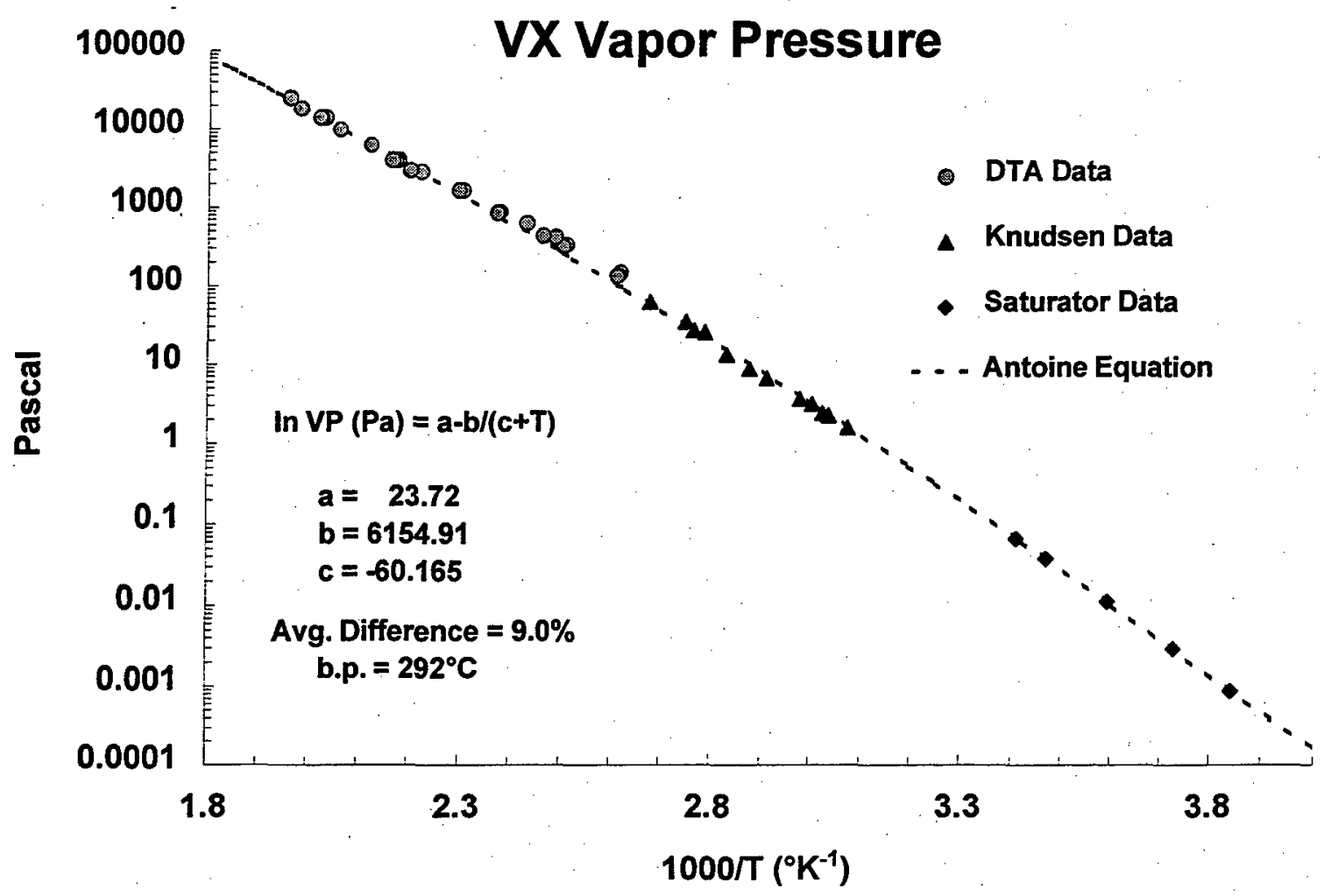

Figure 3. VX Vapor Pressure Plot Showing Previous Literature Data, New Saturator Data, and Antoine Fit to all Data

Table 1. Measured and Corrected Vapor Pressure for VX and Sample Volumes

\begin{tabular}{|c|c|c|c|}
\hline $\begin{array}{l}\text { Temperature } \\
\left({ }^{\circ} \mathrm{C}\right)\end{array}$ & $\begin{array}{c}\text { Measured } \\
\text { VX VP } \\
\text { (milliPascal) }\end{array}$ & $\begin{array}{c}\text { Corrected } \\
\text { VX VP* } \\
\text { (milliPascal) }\end{array}$ & $\begin{array}{c}\text { Sample } \\
\text { Volume (scc) }\end{array}$ \\
\hline
\end{tabular}

$\begin{array}{cccc}20 & 62.2 & 65.8 & 5 \\ 15 & 35.1 & 37.0 & 10 \\ 5 & 10.5 & 11.2 & 40 \\ -5 & 2.75 & 2.9 & 120 \\ -13 & 0.81 & 0.86 & 500\end{array}$

*Corrected using Raoult's Law by dividing measured vapor pressure by VX mole fraction (0.946). 
Table 2. Measured VX Vapor Pressure, Calculated Vapor Pressure Based on Updated Antoine Parameters, and Percent Difference.

\begin{tabular}{|c|c|c|c|}
\hline \multicolumn{4}{|c|}{ Antoine Coefficients } \\
\hline & $\mathbf{a}$ & 23.72 & \\
\hline & b & 6154.9 & \\
\hline & c & -60.16 & $\cdot$ \\
\hline & Average Difference & $9.0 \%$ & \\
\hline & Calculated Boiling Point & $292^{\circ} \mathrm{C}$ & \\
\hline $\mathrm{T}\left({ }^{\circ} \mathrm{C}\right)$ & Measured VP (Pa) & Calculated VP (Pa) & Difference (\%) \\
\hline \multicolumn{4}{|c|}{ Saturator Data } \\
\hline-13.0 & 0.00086 & 0.000860 & 0.0 \\
\hline-5.0 & 0.0029 & 0.00281 & 3.1 \\
\hline 5.0 & 0.011 & 0.0109 & 2.1 \\
\hline 15.0 & 0.037 & 0.0377 & 1.4 \\
\hline 20.0 & 0.066 & 0.0672 & 2.2 \\
\hline \multicolumn{4}{|c|}{ Knudsen Data } \\
\hline 52.0 & 1.57 & 1.633 & 3.8 \\
\hline 56.0 & 2.29 & 2.306 & 0.6 \\
\hline 57.3 & 2.40 & 2.574 & 7.3 \\
\hline 59.6 & 3.12 & 3.120 & 0.0 \\
\hline 62.4 & 3.68 & 3.925 & 6.7 \\
\hline 70.2 & 6.73 & 7.264 & 7.9 \\
\hline 74.5 & 8.79 & 10.05 & 14.4 \\
\hline 80.0 & 13.3 & 15.03 & 13.3 \\
\hline 85.7 & 25.8 & 22.44 & 13.1 \\
\hline 88.5 & 27.2 & 27.17 & 0.2 \\
\hline 90.5 & 34.7 & 31.08 & 10.5 \\
\hline 100.2 & 62.4 & 58.25 & 6.7 \\
\hline \multicolumn{4}{|l|}{ DTA Data } \\
\hline 108.5 & 147 & 96.74 & 34.0 \\
\hline 109.5 & 133 & 102.7 & 23.0 \\
\hline 125.0 & 333 & 246.3 & 26.1 \\
\hline 126.0 & 320 & 259.9 & 18.8 \\
\hline 128.5 & 413 & 296.9 . & 28.2 \\
\hline 132.5 & 433 & 365.7 & 15.6 \\
\hline 138.0 & 627 & 483.5 & 22.8 \\
\hline 147.0 & 867 & 749.6 & 13.5 \\
\hline 148.0 & 853 & 785.9 & 7.9 \\
\hline 160.5 & 1626 & 1391 & 14.5 \\
\hline . 162.0 & 1626 & 1485 & 8.7 \\
\hline 176.5 & 2853 & 2736 & 4.1 \\
\hline 181.0 & 2920 & 3278 & 12.3 \\
\hline 186.0 & 3986 & 3986 & 0.0 \\
\hline 187.0 & 3986 & 4143 & 3.9 \\
\hline 188.5 & 3986 & 4388 & 10.1 \\
\hline 198.0 & 6173 & 6250 & 1.3 \\
\hline 212.0 & 9692 & 10240 & 5.7 \\
\hline 219.0 & 14000 & 12950 & 7.5 \\
\hline 221.0 & 14000 & 13830 & 1.2 \\
\hline 221.5 & 14000 & 14060 & 0.4 \\
\hline 231.0 & 18120 & 19040 & 5.1 \\
\hline 231.5 & 18120 & 19340 & 6.7 \\
\hline 237.0 & 24490 & 22900 & 6.5 \\
\hline
\end{tabular}


Table 3. Calculated Vapor Pressure of VX Over the Ambient Temperature Range Calculated Using Antoine Equations Derived from all Data and by Savage and Fielder. Volatility calculated based on this work. (Asterisks indicate extrapolation).

\begin{tabular}{|c|c|c|c|}
\hline $\begin{array}{c}\text { Temperature } \\
\left({ }^{\circ} \mathrm{C}\right)\end{array}$ & $\begin{array}{l}\text { Vapor Pressure (Pa) } \\
\text { This Work }\end{array}$ & $\begin{array}{l}\text { Vapor Pressure }(\mathrm{Pa}) \\
\text { Savage and Fielder }\end{array}$ & $\begin{array}{c}\text { Calculated } \\
\text { Volatility }\left(\mathrm{mg} / \mathrm{m}^{3}\right) \\
\text { Based on This Work }\end{array}$ \\
\hline$-40^{*}$ & $7.06 \mathrm{E}-06$ & $5.92 \mathrm{E}-07$ & $9.73 \mathrm{E}-04$ \\
\hline$-35^{*}$ & $1.92 \mathrm{E}-05$ & $2.19 \mathrm{E}-06$ & $2.59 \mathrm{E}-03$ \\
\hline$-30^{*}$ & 4.93E-05 & 7.39E-06 & $6.52 \mathrm{E}-03$ \\
\hline$-25 *$ & $1.21 \mathrm{E}-04$ & $2.30 \mathrm{E}-05$ & 0.0156 \\
\hline$-20^{*}$ & $2.82 \mathrm{E}-04$ & $6.64 \mathrm{E}-05$ & 0.0358 \\
\hline$-15^{*}$ & $6.30 \mathrm{E}-04$ & $1.79 \mathrm{E}-04$ & 0.0785 \\
\hline-10 & $1.36 \mathrm{E}-03$ & 4.55E-04 & 0.166 \\
\hline-5 & $2.81 \mathrm{E}-03$ & $1.09 \mathrm{E}-03$ & 0.337 \\
\hline 0 & $5.63 \mathrm{E}-03$ & $2.49 \mathrm{E}-03$ & 0.662 \\
\hline 5 & 0.0109 & $5.43 \mathrm{E}-03$ & 1.26 \\
\hline 10 & 0.0206 & 0.0113 & 2.34 \\
\hline 15 & 0.0377 & 0.0228 & 4.20 \\
\hline 20 & 0.0672 & 0.0441 & 7.38 \\
\hline 25 & 0.117 & 0.0825 & 12.6 \\
\hline 30 & 0.199 & 0.150 & 21.2 \\
\hline 35 & 0.332 & 0.264 & 34.7 \\
\hline 40 & 0.542 & 0.454 & 55.7 \\
\hline 45 & 0.869 & 0.760 & 87.9 \\
\hline 50 & 1.37 & 1.24 & 136 \\
\hline 55 & 2.12 & 1.99 & 208 \\
\hline 60 & 3.22 & 3.13 & 311 \\
\hline
\end{tabular}




\section{LITERATURE CITED}

1. ECBC Notebook \#NB 8343 (U).

2. Savage, J. J., and Fielder, D., The Vapor Pressure of Chemical Agents GD, VX, EA 2223, EA 3547, EA 3580, EA 5365, and EA 5533, EC-TR-76058, Aberdeen Proving Ground, MD, August 1976, UNCLASSIFIED Report (AD-B013 164).

3. American Society for Testing and Materials Standard Test Method for Vapor Pressure, ASTM E1194-87.

4. Smardzewski, R. R., J. Chem Phys. Vol. 68, No. 6, p. 2878, 15 Mar 1978.

5. Tevault, D.E., Keller, J., and Parsons, J.A., "Vapor Pressure of Dimethly Methylphosphonate," In Proceedings of the 1998 ERDEC Scientific Conference on Chemical Defense Research, 17-20 November 1999, ECBC-SP-004, pp 815-824, U.S. Army Edgewood Chemical Biological Center, Aberdeen Proving Ground, MD, July 1999, UNCLASSIFIED Proceedings. 1998.

6. Handbook of Chemistry and Physics, $78^{\text {th }}$ ed., pp 6-8, CRC Press, Incorporated, 1997-

7. Kosolapoff, G.M., J. Chem Soc., p 2964, 1955.

8. Reid, R.C., Prausnitz, J.M., and Poling, B.E., The Properties of Gases and Liquids $4^{\text {th }}$ ed., McGraw-Hill, New York, NY, 1987. 


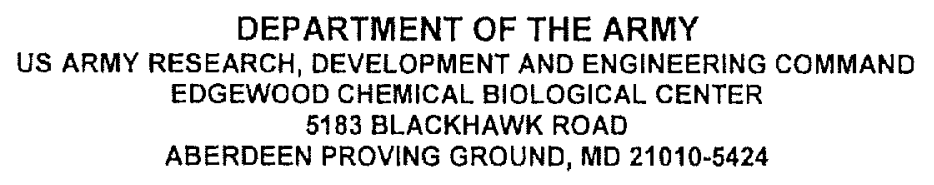

RDCB-DPC-RS

MEMORANDUM FOR Defense Technical Information Center (DTIC), 8725 John J. Kingman Road, Fort Belvoir, VA 22060-6218.

SUBJECT: Change in Limitation (Public Release of Information)

1. The purpose of this memorandum is to recommend the Release of Information to the General Public regarding Edgewood Arsenal Technical Memorandum (EATM 134-2), Viscosity of $V X$ in the Temperature Range -4 degrees - -40 degrees $F$, dated May 1969; and Edgewood Arsenal Technical Report (EC-TR-76058), The Vapor Pressure of Chemical Agents GD, VX, EA 2223, EA 3547, EA 3580, EA 5365 and EA 5593, dated August 1976. The first memorandum was Confidential and was previously downgraded to Unclassified on $20 \mathrm{Mar} 1978$. The DTIC Number is AD-501931. The second report is Unclassified and the DTIC Number is ADB-013164.

2. This document has been reviewed by Subject Matter Experts from the Edgewood Chemical Biological Center (ECBC) on Aberdeen Proving Ground, Maryland and deemed releasable to the General Public. Request that this document be properly identified and appropriately marked.

3. As the Security Manager for the documents in question, I concur with the recommendations made by the ECBC Review Team.

4. Point of contact for this action is the Information Security Officer, Ronald Stafford at $410-436-6810$ or the undersigned at $410-436-7232$.

Encl

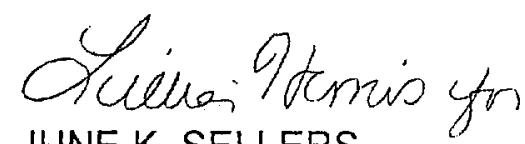

JUNE K. SELLERS

ECBC Security and Surety Manager 